\section{Fertility and Reproductive Pathways in Diploid and Triploid Miscanthus sinensis}

\author{
Todd J. Rounsaville ${ }^{1}$, Darren H. Touchell ${ }^{2,4}$, and Thomas G. Ranney ${ }^{3}$ \\ Mountain Crop Improvement Lab ${ }^{T M}$, Department of Horticultural Science, \\ Mountain Horticultural Crops Research and Extension Center, North Carolina \\ State University, 455 Research Drive, Mills River, NC 28759-3423
}

Additional index words. aneuploidy, invasive, polyploidy, plant breeding, propagule pressure, reproductive biology, sterility, ornamental grasses

\begin{abstract}
Miscanthus sinensis Andersson is a popular ornamental grass and has additional potential as a bioenergy crop. In some regards, the ability of $M$. sinensis to withstand a broad range of climatic and cultural conditions is desirable, but its propensity to rapidly colonize open and disturbed environments has allowed it to naturalize and become weedy in some regions in the United States. Considering the value of this crop, the development and documentation of infertile clones would be desirable. Triploid plants were evaluated for male and female fertility using pollen viability staining and seed set and germination, respectively. Pollen viability staining, seed set, and seed germination from triploid plants were reduced compared with diploids but varied considerably within each cytotype. Overall, relative female fertility of individual triploids clones $[(\%$ seed set $\times \%$ germination for triploid $) /(\%$ seed set $\times \%$ germination for diploid control $)]$ was reduced substantially and ranged from $49 \%$ to $0.7 \%$. Additionally, the reproductive pathways of triploid plants were examined by evaluating the $2 \mathrm{C}$ genome sizes of progeny derived from open pollination. The limited progeny arising from open-pollinated triploids were predominantly aneuploids with $2 \mathrm{C}$ genome sizes intermediate between diploids and triploids. There was no clear evidence of apomixis, selfing, or triploid $\times$ triploid fertilization events observed among triploid parents. Formation of unreduced gametes was rare for both ploidy levels $(\approx 1 \%)$. The considerable reduction in female fertility in some triploid clones combined with the limited production of primarily aneuploid progeny provides highly infertile alternatives to existing diploid cultivars.
\end{abstract}

The genus Miscanthus Andersson contains $\approx 20$ species of perennial C4 grasses predominantly from Asia (Glowacka and Jezowski, 2009; Hodkinson et al., 2002). Genetic diversity is high within Miscanthus and has allowed some species to evolve populations adapted to highly diverse environments (Heaton et al., 2010). Miscanthus spp. have long been recognized for their potential as ornamentals, and maiden grass or Japanese silver grass $(M$. sinensis) has been grown in the United States since being introduced in the late 19th century

Received for publication 7 July 2011. Accepted for publication 11 Aug. 2011.

This research was funded, in part, by the North Carolina Agricultural Research Service (NCARS), Raleigh, NC, and the U.S. Department of Agriculture Agricultural Research Service, Floriculture and Nursery Research Initiative, Beltsville, MD.

Thanks are expressed to the North Carolina Biotechnology Center, Biofuels Center of North Carolina, Kenan Institute, and Hoffman Nursery for support of this research. Technical assistance of Kelly Gaskill, Irene Palmer, and Jeremy Smith is gratefully acknowledged.

This research is from a MS thesis by the senior author. ${ }^{1}$ Graduate Research Assistant.

${ }^{2}$ Research Associate.

${ }^{3}$ Professor.

${ }^{4}$ To whom reprint requests should be addressed; e-mail darren_touchell@ncsu.edu. is native to China and Japan and, like many Miscanthus spp., is notable for its high water use efficiency and the ability to fix nitrogen through a bacterial symbiotic relationship (Eckert et al., 2001; Stewart et al., 2009). Several hundred years of cultivation has given rise to over $100 \mathrm{M}$. sinensis cultivars, featuring a range of heights, foliage types, and variegations (vertical or horizontal banding) (Darke, 2007). In North America, M. sinensis is one of the most widely planted of all ornamental grasses as a result of its colorful and dense inflorescences, durability, and capacity to thrive in USDA hardiness zones 4 to 9 (Meyer and Tchida, 1999; Wilson and Knox, 2006). The merits of $M$. sinensis have led to over 50 new selections introduced within the past 25 years (Wilson and Knox, 2006). More recently, $M$. sinensis has shown promise as a potential crop for bioenergy applications, particularly in northern latitudes where less cold-hardy grasses are unreliable (Glowacka and Jezowski, 2009; Heaton et al., 2010).

Miscanthus sinensis is strictly a clumpforming grass, which spreads naturally over short distances by wind-blown seeds (Darke, 2007; Stewart et al., 2009). Naturalization of this species, predominantly in open or disturbed environments, can be significant and problematic (Barney and DiTomasa, 2008; Meyer and Tchida, 1999). The first documented naturali-
(Quinn et al., 2010). Miscanthus sinenesis zations in the United States were reported in Washington, DC, New York, and Florida in 1913 (Quinn et al., 2010). Wilson and Knox (2006) noted that M. sinensis has since naturalized in at least 25 states, of which many include it on invasive watch lists. Although $M$. sinensis is an early successional, pioneer species that typically colonizes open disturbed sites (Ohtsuka et al., 1993; Stewart et al., 2009; Tsuyuzaki and Hase, 2005), it can be a prolific weed in managed landscapes such as roadsides and pastures (Hirata et al., 2007).

Reproductive biology of $M$. sinensis has been studied in both wild populations and cultivars of diploid plants. Stewart et al. (2009) documented seed set (percentage of florets setting seed) among wild populations in Japan between $3 \%$ and $84 \%$ depending on plant density as well as genetic and environmental factors. Among cultivated varieties, seed set and germination have been shown to vary as a function of location and genotype (Meyer and Tchida, 1999; Wilson and Knox, 2006). Cultivars of $M$. sinensis are generally regarded as self-incompatible, and effective pollination and seed set requires different genotypes in close proximity (less than $4 \mathrm{~m}$ ) with ample pollen load and overlapping bloom times (Chiang et al., 2003; Stewart et al., 2009). Pollen grains of Miscanthus are trinucleate, which is generally indicative of rapid germination on stigmas and short-lived viability (Friedman and Barrett, 2011). There are, however, no published reports on male (pollen) fertility for Miscanthus sp.

Miscanthus sp. have a base chromosome number of 19 and $M$. sinensis varieties and cultivars have been reported as diploid with $2 n=2 x=38$ (Rayburn et al., 2009). Hybridizations between species as well as across ploidy levels have been documented, including $M$. $\times$ giganteus $(2 n=3 x=57)$, a naturally occurring triploid hybrid between diploid $M$. sinensis and tetraploid M. sacchariflorus (Glowacka and Jezowski, 2009). As a result of the inability of three chromosome sets to divide equally during meiosis, triploid plants often suffer from reduced fertility or complete sterility (LindeLaursen, 1993; Ramsey and Schemske, 1998). For example, $M$. ×giganteus is widely reported to be highly infertile (Rayburn et al., 2009). However, in some cases, triploids can have limited fertility resulting from formation of apomictic embryos, unreduced gametes, and the union of aneuploid gametes (Lim et al., 2003; Lo et al., 2009; Ramsey and Schemske, 1998; Sears, 1953). Determination of 2C genome size of progeny from triploid parents can elucidate the reproductive pathway by which seedlings originated (Doležel and Bartos, 2005).

Development of new triploid $M$. sinensis may produce infertile plants with low reproductive potential. Infertile forms of $M$. sinensis would be valuable alternatives for landscape and bioenergy applications. Researchers at the North Carolina State University, Mountain Crop Improvement Laboratory ${ }^{\mathrm{TM}}$ (MCI Laboratory), Mills River, NC, have developed a population of triploid $M$. sinensis, of which 18 clones were selected for having desirable ornamental and/or growth characteristics. Unlike 
the full sterility documented in M. × giganteus, some of these triploid M. sinensis were observed to produce both pollen and low numbers of seeds. To evaluate the reproductive potential of these plants, it is necessary to evaluate and document the fertility among each of the selected clones. Therefore, the objectives of this study were to evaluate selected triploid clones of $M$. sinensis for male and female fertility, examine the reproductive pathways of intraploid and interploid matings, and determine the $2 \mathrm{C}$ genome sizes of progeny derived from these crosses.

\section{Materials and Methods}

Plant material. The taxa used in this study consisted of five diploid (2x) and 18 triploid (3x) clones of $M$. sinensis (Table 1). Diploid plants included four commercially available cultivars and one hybrid developed at the MCI Laboratory. Tetraploid plants were developed by hybridizing $M$. sinensis 'Variegatus' with 'Strictus' followed by in vitro polypoid induction using procedures similar to Herbert et al. (2010). Triploid plants were generated by crossing these autotetraploids with selected diploids and subsequently recovered by embryo rescue. Triploid taxa selected for this study were chosen from 700 genotypes after 2 years of field trials.

Experimental design. Divisions of each genotype were propagated in 1-gallon pots and field-planted in mid-May 2010 using a randomized complete block design consisting of five replicated blocks. Each block contained 38 plants, including one of each triploid clone and four (subsamples) of each diploid clone to ensure adequate pollination. Plants were spaced on 46-cm centers in cultivated (mounded) rows with $1.2 \mathrm{~m}$ between rows and irrigated as needed throughout the summer using drip irrigation.

Evaluating male fertility. Male fertility was assessed by estimating the viability of fresh pollen with acetocarmine staining. Pollen was collected over a 2-week period in late Aug. 2010. Sampling was conducted randomly within blocks, one block at a time. Inflorescences were collected between 0800 and $1000 \mathrm{HR}$, placed in a sealed plastic bag, and immediately brought into the laboratory for assessment. Fresh pollen was dusted onto a microscope slide by gently shaking the inflorescence. Pollen grains were stained by adding one to two drops of $1 \%$ acetocarmine to the microscope slide and incubated for $30 \mathrm{~min}$ at room temperature $\left(23^{\circ} \mathrm{C}\right)$. Pollen grains that were well-stained and well-formed were scored as viable with 100 or more grains scored per replicate. Pollen viability was calculated by number of grains scored as viable/number of grains counted.

Evaluating female fertility. Female fertility was assessed by determining percentage of seed set and percentage of viable seeds based on germination. Whole inflorescences (up to 10 per replicate) were collected in Oct. 2010 and stored in large paper bags at room temperature until dry ( 8 weeks). For each replicate, spikelets were randomly sampled from different inflorescences. Up to 1000 individual florets were examined per replicate (or until 100 seeds were extracted). Seed set was calculated by number of seeds counted/number of florets examined.

Seeds collected during the seed set experiment were germinated one block at a time. Seeds were dehulled, placed on blotter paper (SDB3.5; Anchor Paper Co., St. Paul, MN), and moistened with distilled $\mathrm{H}_{2} \mathrm{O}$ in plastic petri dishes $(100 \mathrm{~mm} \times 15 \mathrm{~mm})$. Petri dishes were sealed with parafilm and kept at $23 \pm 2{ }^{\circ} \mathrm{C}$ with a $16-\mathrm{h}$ photoperiod of $30 \mu \mathrm{mol} \cdot \mathrm{m}^{-2} \cdot \mathrm{s}^{-1}$ (400 to $700 \mathrm{~nm}$ ) provided by cool-white fluorescent lamps. Germination was recorded after 4 weeks using radical emergence as the criterion. Total germination was calculated as seeds germinated/total seeds. Overall female fertility (percent viable seed set) was determined by: $\{[$ seed set $(\%) \times$ seed germination $(\%)] / 100\}$. Additionally, relative female fertility (overall female fertility of each clone in relation to the diploid control with the highest overall female fertility) was determined as: [ $\%$ seed set $\times \%$ germination for given clone $) /(\%$ seed set $\times \%$ germination for diploid control)].

Determining $2 \mathrm{C}$ genome size and ploidy level. Flow cytometric analysis was used to determine the $2 \mathrm{C}$ genome size and ploidy level of all parents and offspring. Young leaf tissue $\left(\approx 0.5 \mathrm{~cm}^{2}\right)$ was finely chopped within $0.4 \mathrm{~mL}$ of nuclei extraction buffer along with Pisum sativum L. 'Ctirad', an internal standard with a known $2 \mathrm{C}$ genome size of 8.75 picograms (pg) (Doležel et al., 1998). Nuclei were filtered using a $50-\mu \mathrm{m}$ nylon filter

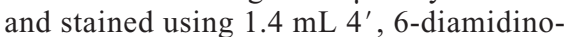
2-phenylindole (DAPI) staining buffer. Genome size (DNA content of the nonreplicated chromosome complement) was analyzed with a Partec PA-II flow cytometer (Partec, Münster, Germany). Holoploid, 2C genome size was calculated as: $2 \mathrm{C}=$ genome size of standard $\times$ (mean fluorescence value of sample/mean fluorescence value of standard).

Evaluating reproductive pathways. From each germination trial (for three complete blocks), six germinated seedlings were chosen at random and moved to a fresh petri dish.

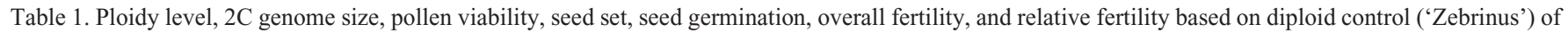
selected Miscanthus sinensis genotypes.

\begin{tabular}{|c|c|c|c|c|c|c|c|}
\hline & $\begin{array}{c}\text { Ploidy } \\
\text { level (x) }\end{array}$ & $\begin{array}{l}2 \mathrm{C} \text { genome } \\
\text { size }(\mathrm{pg})^{\mathrm{z}}\end{array}$ & $\begin{array}{c}\text { Pollen } \\
\text { viability }(\%)^{\mathrm{y}}\end{array}$ & Seed set $(\%)$ & Germination $(\%)$ & $\begin{array}{c}\text { Overall } \\
\text { fertility }(\%)^{\mathrm{x}}\end{array}$ & $\begin{array}{l}\text { Relative } \\
\text { fertility }^{\mathrm{w}}\end{array}$ \\
\hline M. sinensis 'Gracillimus' 2004-256 & 2 & $3.97 \pm 0.03^{v}$ & $73.4 \pm 5.0$ abcdef & $50.2 \pm 6.2 \mathrm{c}$ & $44.6 \pm 4.7 \mathrm{~d}$ & $24.8 \mathrm{c}$ & $44.8 \mathrm{c}$ \\
\hline M. sinensis 'Superstripe' 2006-238 & 2 & $4.02 \pm 0.01$ & $77.0 \pm 25 \mathrm{a}$ & $69.8 \pm 2.5 b$ & $71.2 \pm 3.4 \mathrm{ab}$ & $49.7 \mathrm{ab}$ & $91.0 \mathrm{ab}$ \\
\hline M. sinensis 'Variegatus' 2004-257 & 2 & $3.94 \pm 0.05$ & $75.0 \pm 3.1 \mathrm{abc}$ & $84.4 \pm 2.7 \mathrm{a}$ & $52.9 \pm 3.5 \mathrm{~d}$ & $43.9 \mathrm{~b}$ & $79.4 \mathrm{~b}$ \\
\hline M. sinensis 'Zebrinus' 2004-259 & 2 & $4.08 \pm 0.02$ & $74.0 \pm 3.3$ abcde & $74.4 \pm 2.1 \mathrm{~b}$ & $73.4 \pm 4.8 \mathrm{a}$ & $55.3 \mathrm{a}$ & $100.0 \mathrm{a}$ \\
\hline M. sinensis H2006-026-006 & 2 & $4.01 \pm 0.00$ & $76.4 \pm 3.3 \mathrm{ab}$ & $66.3 \pm 2.9 \mathrm{~b}$ & $75.3 \pm 3.3 \mathrm{a}$ & $49.9 \mathrm{ab}$ & $91.4 \mathrm{ab}$ \\
\hline M. sinensis H2008-025-002 & 3 & $5.68 \pm 0.02$ & $72.2 \pm 4.9$ abcde & $23.0 \pm 4.6 \mathrm{eh}$ & $38.8 \pm 5.8 \mathrm{~d}$ & $9.1 \mathrm{de}$ & $16.5 \mathrm{de}$ \\
\hline M. sinensis H2008-026-010 & 3 & $5.82 \pm 0.01$ & $60.4 \pm 6.4$ efghi & $7.9 \pm 1.5$ hijk & $31.7 \pm 7.4$ ghij & $2.8 \mathrm{de}$ & $5.1 \mathrm{de}$ \\
\hline M. sinensis H2008-027-003 & 3 & $5.91 \pm 0.05$ & $60.0 \pm 4.2 \mathrm{fghi}$ & $16.5 \pm 1.9 \mathrm{e}$ & $23.2 \pm 1.3 \mathrm{ij}$ & $3.8 \mathrm{de}$ & $6.8 \mathrm{de}$ \\
\hline M. sinensis H2008-036-025 & 3 & $5.62 \pm 0.01$ & $55.6 \pm 2.4 \mathrm{ghi}$ & $7.3 \pm 1.2$ hijk & $35.4 \pm 4.9$ efghij & $2.4 \mathrm{de}$ & $4.3 \mathrm{de}$ \\
\hline M. sinensis H2008-061-001 & 3 & $5.65 \pm 0.02$ & $62.0 \pm 2.6$ defghi & $52.1 \pm 4.6 \mathrm{c}$ & $50.8 \pm 5.9 \mathrm{cdefg}$ & $27.2 \mathrm{c}$ & $49.2 \mathrm{c}$ \\
\hline M. sinensis H2008-063-011 & 3 & $5.47 \pm 0.02$ & $53.3 \pm 4.5 \mathrm{ghi}$ & $5.6 \pm 3.7$ hijk & $31.4 \pm 9.9 \mathrm{fghj}$ & $2.5 \mathrm{de}$ & $4.4 \mathrm{de}$ \\
\hline M. sinensis H2008-064-009 & 3 & $5.73 \pm 0.02$ & $55.2 \pm 3.8 \mathrm{hi}$ & $32.6 \pm 6.8 \mathrm{de}$ & $23.0 \pm 8.2 \mathrm{ij}$ & $9.6 \mathrm{de}$ & $17.3 \mathrm{de}$ \\
\hline M. sinensis H2008-065-003 & 3 & $5.81 \pm 0.02$ & $63.3 \pm 2.8$ cdefghi & $24.9 \pm 1.3 \mathrm{eg}$ & $69.0 \pm 8.1 \mathrm{abc}$ & $17.0 \mathrm{~cd}$ & $30.7 \mathrm{~cd}$ \\
\hline M. sinensis H2008-065-006 & 3 & $5.80 \pm 0.02$ & $59.2 \pm 6.7 \mathrm{fgh}$ & $12.9 \pm 1.0$ fghijk & $50.8 \pm 5.7 \mathrm{cdefg}$ & $6.5 \mathrm{de}$ & $11.8 \mathrm{de}$ \\
\hline M. sinensis H2008-067-021 & 3 & $5.62 \pm 0.03$ & $65.4 \pm 3.3$ abcdefgh & $27.6 \pm 4.5 \mathrm{ef}$ & $16.0 \pm 2.7 \mathrm{j}$ & $4.3 \mathrm{de}$ & $7.8 \mathrm{de}$ \\
\hline M. sinensis H2008-071-002 & 3 & $5.77 \pm 0.01$ & $50.3 \pm 6.5 \mathrm{i}$ & $15.8 \pm 3.2$ fghijk & $42.2 \pm 3.7$ defghi & $6.5 \mathrm{de}$ & $11.7 \mathrm{de}$ \\
\hline M. sinensis H2008-071-009 & 3 & $5.65 \pm 0.03$ & $54.5 \pm 4.3 \mathrm{ghi}$ & $20.1 \pm 3.7$ efghij & $48.3 \pm 3.1$ defgh & $9.9 \mathrm{de}$ & $18.5 \mathrm{de}$ \\
\hline M. sinensis H2008-072-001 & 3 & $5.89 \pm 0.04$ & $62.3 \pm 0.8$ cdefghi & $12.6 \pm 2.8$ fghijk & $52.5 \pm 9.0 \mathrm{cdef}$ & $6.4 \mathrm{de}$ & $11.6 \mathrm{de}$ \\
\hline M. sinensis H2008-084-002 & 3 & $5.80 \pm 0.01$ & $70.5 \pm 7.0$ abcdef & $20.9 \pm 8.1$ efghi & $21.3 \pm 7.0 \mathrm{ij}$ & $6.4 \mathrm{de}$ & $11.9 \mathrm{de}$ \\
\hline M. sinensis H2008-087-001 & 3 & $5.60 \pm 0.02$ & $52.0 \pm 5.3 \mathrm{hi}$ & $8.9 \pm 1.0$ ghijk & $54.8 \pm 8.5 \mathrm{cde}$ & $5.1 \mathrm{de}$ & 8.9 de \\
\hline M. sinensis H2008-091-004 & 3 & $5.86 \pm 0.02$ & $64.6 \pm 5.9 \mathrm{bcdefgh}$ & $0.7 \pm 0.1 \mathrm{k}$ & $56.3 \pm 7.1 \mathrm{bcd}$ & $0.4 \mathrm{e}$ & $0.7 \mathrm{e}$ \\
\hline M. sinensis H2008-130-001 & 3 & $5.87 \pm 0.01$ & $58.6 \pm 3.0 \mathrm{fghi}$ & $6.3 \pm 1.9 \mathrm{ijk}$ & $27.5 \pm 5.1 \mathrm{ij}$ & $1.7 \mathrm{de}$ & $3.1 \mathrm{de}$ \\
\hline M. sinensis H2008-131-001 & 3 & $5.91 \pm 0.01$ & $67.2 \pm 3.3$ abcdefg & $45.9 \pm 7.5 \mathrm{~cd}$ & $28.4 \pm 5.9$ hij & 12.7 cde & $23.0 \mathrm{cde}$ \\
\hline
\end{tabular}

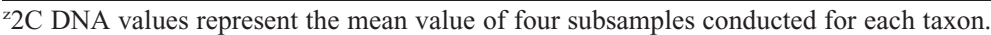

'Mean separation within columns by Fisher's least significant difference at $P \leq 0.05$.

${ }^{\mathrm{x}}$ Calculated as (seed set $\times$ seed germination) $/ 100$.

${ }^{\text {w}}$ Calculated as overall fertility/(0.546), where 54.6 is the percentage fertility of 'Zebrinus', a diploid control.

${ }^{v}$ Values are means \pm 1 SEM. 
After another 1 to 2 weeks of growth, 568 seedlings were subjected to flow cytometric analysis following the procedures described previously. Data from all studies were subjected to analysis of variance procedures and means separated using Fisher's least significant difference with SAS Version 9.1 (SAS Inst. Inc., Cary, NC).

\section{Results and Discussion}

The mean $2 \mathrm{C}$ genome size of the five diploid genotypes was $4.02 \pm 0.03$ (SEM) pg, whereas the mean for the 18 triploid genotypes was $5.75 \pm 0.03$ (SEM) pg (Table 1). The genome size of triploids was slightly less than 1.5 times that of the diploids, yet intermediate between diploid and tetraploid parents [tetraploids had a mean $2 \mathrm{C}$ genome size of $7.52 \pm 0.04$ (SEM) $\mathrm{pg}]$. The decrease in $1 \mathrm{Cx}$ genome size (genome size of one complete set of chromosomes) with increasing ploidy level may indicate genomic downsizing, a phenomenon often observed after chromosome doubling (Buggs et al., 2009; Leitch et al., 2008; Soltis et al., 2003).

Male fertility. Pollen stainability in triploid plants ranged from $50 \%$ to $72 \%$ (60\% average) compared with $73 \%$ to $77 \%$ ( $74 \%$ average) for the diploid controls (Table 1). Although acetocarmine staining is used routinely to estimate pollen viability, this dye indiscriminately stains DNA and cytoplasmic proteins and may stain pollen grains that are not fully functional (MacFarlane Smith et al., 1989; Slomka et al., 2010) and can thereby overestimate pollen viability. Pollen germination is a preferable method for more accurately assessing viability. However, like many grass species, pollen of Miscanthus is short-lived and efforts to develop reliable germination protocols have been unsuccessful.

Female fertility. Seed set was significantly lower in triploids compared with diploids $(P<$ $0.0001)$. Seed set also differed within diploid cultivars and within triploid cultivars $(P<$ 0.0001) (Table 1). Seed set data for diploid plants ranged from $50 \%$ for 'Gracillimus' to $84 \%$ for 'Variegatus', demonstrating that diploid cultivars can vary substantially in this trait. Among triploid plants, seed set varied considerable by genotype, ranging from $0.7 \%$ for $\mathrm{H} 2008-091-004$ to $52 \%$ for $\mathrm{H} 2008-061$ 001 . Of the 18 triploids used in this research, six had less than $10 \%$ seed set.

Miscanthus seed began germinating within 3 to $4 \mathrm{~d}$ after imbibing and after 4 weeks no further germination was observed. Similar to seed set, there was a significant overall reduction in germination in triploids compared with diploids $(P<0.0001)$. Furthermore, germination differed among both diploid and triploid cultivars $(P<0.0001)$ (Table 1$)$. Germination in diploid plants ranged from $45 \%$ for 'Gracillimus' to $75 \%$ for H2006-026-006. Because we did not conduct post-germination viability tests, it is possible that some ungerminated seed was viable and dormant. In comparison, Wilson and Knox (2006) assessed both germination and post germination viability through tetrazolium staining. Their results estimated that germination of viable seed for 'Gracillimus', 'Variegatus', and 'Zebrinus' ranged from $87 \%$ to $100 \%, 88 \%$ to $100 \%$, and $94 \%$ to $100 \%$, respectively, indicating that germination is a good indicator of viability. Furthermore, we observed higher germination in 'Variegatus' (53\%) and 'Zebrinus' (73\%) compared with Meyer and Tchida (1999) who reported a maximum of $16 \%$ and $60 \%$, respectively. Germination among our triploid plants ranged from $16 \%$ for $\mathrm{H} 2008-067-021$ to $69 \%$ for H2008-065-003.

Overall female fertility reflects the percentage of viable seed produced among florets (Table 1). Overall female fertility ranged from $25 \%$ to $55 \%$ among diploids compared with $0.4 \%$ to $27 \%$ for triploids. The diploid cultivar Zebrinus had the highest overall female fertility, although it did not have the highest individual seed set or germination. Relative female fertility reflects overall female fertility relative to the most fertile diploid control, 'Zebrinus'. Relative female fertility also showed significant reductions in triploid plants with eight triploids having less than $10 \%$ relative fertility and four triploids having less than 5\% relative fertility. The most significant reduction in fertility was observed with H2008-091-004, which had a relative fertility of $0.7 \%$ when compared with the diploid control.

Reproductive pathways. Genome sizes (2C) recorded from 568 progeny of openpollinated diploid and triploid cytotypes provide insight into their reproductive pathways (Fig. 1). The majority (99\%) of seedlings derived from open-pollinated diploid maternal parents were diploids with a mean $2 \mathrm{C}$ genome size of $4.13 \pm 0.02$ (SEM) pg. This value is slightly higher $(\approx 0.11 \mathrm{pg})$ than the diploid parents measured at different times and under different conditions and may vary as a result of subtle variation in tissue chemistry and pigments that can interact with the DAPI fluorochrome (Doležel et al., 1998; Ochatt et al., 2011). Fertilization of diploid maternal par- ents with reduced pollen from triploids was rare; however, in four instances (1.4\%), diploid seedlings displayed $2 \mathrm{C}$ genome size between 4.55 and $4.76 \mathrm{pg}$, suggesting diploid $\times$ triploid hybridization. One extreme outlier with $2 \mathrm{C}$ genome size $=6.15 \mathrm{pg}(\approx 3 \mathrm{x})$ was observed among the progeny from diploid maternal parents ( $0.4 \%$ of seedlings). This fertilization event was most likely the result of an unreduced (2n) gamete from one diploid parent pairing with a reduced (n) diploid gamete from a second diploid parent.

The majority of progeny from maternal triploids had $2 \mathrm{C}$ genome sizes intermediate between triploid and diploid parents with a mean of $4.67 \pm 0.01$ (SEM) pg (Fig. 1). We found no clear evidence of triploid $\times$ triploid hybridization (assuming random chromosome assortment in meiosis) or apomixis among triploids, which would result in progeny with $2 \mathrm{C}$ genome sizes of $\approx 5.8$ to $6.3 \mathrm{pg}$. In some plant species, triploids are able to produce viable gametes that contain an exact haploid $(1 x)$ or diploid $(2 x)$ chromosome complement (Norrmann and Quarin, 1987; Sears, 1953). For example, odd ploidy levels are maintained in the triploid grass andropogon (Andropogon ternatus Spr.) through the formation of functional male gametophytes with two sets of chromosomes and female gametophytes with one set of chromosomes (Norrmann and Quarin, 1987). If gametes had complete sets of chromosomes, we would have expected to observe $3 \mathrm{x}$ and $4 \mathrm{x}$ (in addition to $2 \mathrm{x}$ ) progeny, yet no evidence of this was found. Rather, seedlings from tiploid maternal parents displayed a normal distribution of genome sizes indicative of triploid $\times$ diploid hybridization after random chromosome segregation and aneuploid formation similar to Andropogon gerardii Vitman (Norrmann and Keeler, 2003) and vine cacti [Hylocereus (Berger)] hybrids (TelZur et al., 2005). In three cases, seedlings had $2 \mathrm{C}$ genome sizes of $6.39,6.71$, and $7.32 \mathrm{pg}$, substantially greater than their triploid maternal

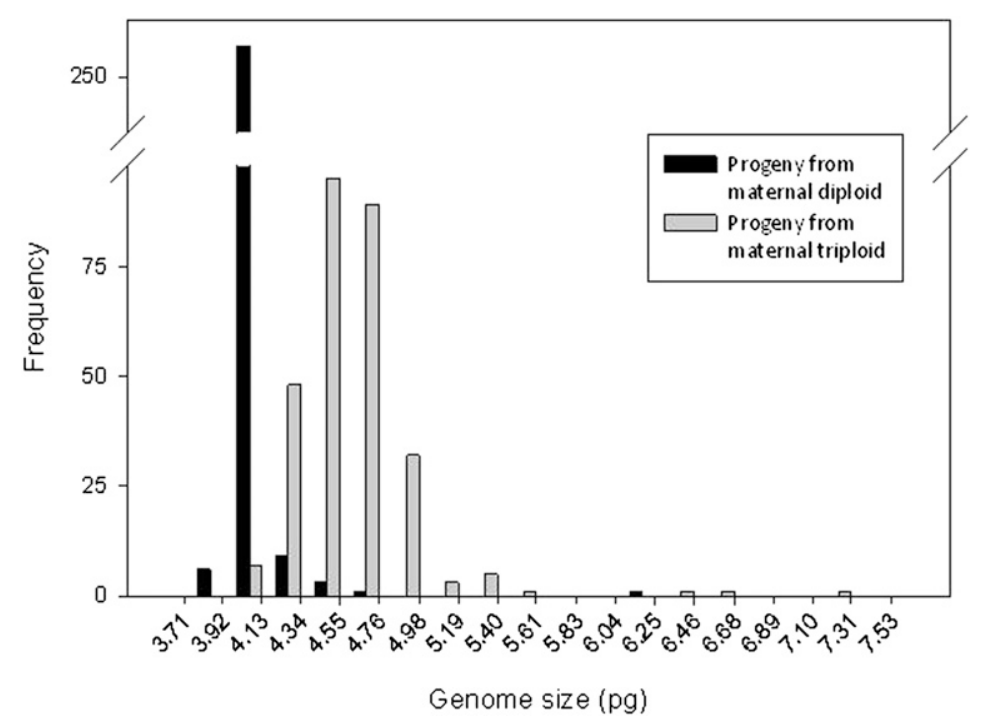

Fig. 1. Frequency distribution of $2 \mathrm{C}$ genome sizes of seedlings derived from open pollinated diploid and triploid Miscanthus sinensis genotypes. Gate width for columns was based on a $95 \%$ prediction interval for diploid plants calculated as the mean $\pm 1.96 \mathrm{sD}=0.21 \mathrm{pg}$. 
parents. These three instances (1.1\%) most likely represent the formation of unreduced gametes from one of the parents. The frequency of unreduced gametes among all progeny was $1.4 \%$.

Propagule pressure is an appraisal of vegetative and gametic structures' differing abilities to advance naturalization of a species (Martínez-Ghersa and Ghersa, 2006). Assessing propagule pressure is an important measure of naturalization potential because unlike the majority of predictive factors, it has a consistent positive association with the establishment of a self-sustaining population (Colautti et al., 2006). Vegetatively, M. sinensis poses very little risk of spread as a result of its strong clumping habit. Native clumps in Japan had radial expansion rates on average of $2.4 \mathrm{~cm}^{2} /$ year over a 9-year period, while at the same time, shoot density in the center of clumps declined year by year (Stewart et al., 2009). Gametic propagule pressure (seed) poses a far greater risk for naturalization of Miscanthus and several factors must be taken into consideration. Although our study shows that seed set of diploids can reach $84 \%$ with numerous nearby pollen donors, seed production in wild populations has been reported to be less than $20 \%$ among plants greater than $4 \mathrm{~m}$ apart (Stewart et al., 2009). However, seed set can be prolific with a mean of 1051 seeds per plant reported in the wild and a mean of 657 seeds (per three inflorescences) from cultivated plants in the United States (Meyer and Tchida, 1999; Stewart et al., 2009).

Decreasing fertility by reductions in pollen viability, seed set, and seed germination mitigates propagule pressure and the potential for plants to naturalize (see Anderson et al., 2006, for review). In particular, curbing fecundity to a point where more individuals are dying than are being established will inevitably lead to a decline in population growth (Jacquart and Knight, 2010; Ramula et al., 2008). For example, reducing fecundity and propagule survival by $60 \%$ was sufficient to cause population decreases in several invasive annual grasses (Tozer et al., 2008). In a study of scotch broom [Cytisus scoparius (L.) Link], Sheppard et al. (2002) estimated that a $62 \%$ reduction in seed set was needed to reverse dominance of this species in native grasslands. Similarly, populations of musk thistle (Carduus nutans L.) were estimated to begin decreasing in size pending a $\approx 69 \%$ decrease in seed production (Shea and Kelly, 1998). Populations of the prolific biennial weed, garlic mustard [Alliaria petiolata (M. Bieb.) Cavara \& Grande], began declining when weevils reduced seed production by $49 \%$ (Davis et al., 2006). Overall, triploids examined in the present study had between $50 \%$ to $99 \%$ reductions in relative fertility compared with diploid controls. This represents a significant decline in fertility, which would reduce the potential for these plants to initially naturalize, particularly for highly infertile clones.

There is legislative precedence for exempting infertile cultivars from sales restriction of weedy species. For example, cultivars of butterfly bush (Buddleia davidii Franch.) documented to produce less than $2 \%$ viable seeds are now considered effectively sterile by the Oregon Department of Agriculture (2011). A stipulation in the aforementioned criteria calls for the presence of abundant pollen donors to ensure legitimate results during testing. Our study included an abundance of diploid pollinators (100 plants) in close proximity to triploids. High levels of seed set among diploids confirmed favorable pollination conditions. In another example based on germination alone, Fine Line ${ }^{\circledR}$ buckthorn (Rhamnus frangula $\mathrm{L}$. 'Ron Williams') is now being marketed as a non-invasive plant based on seed germination of $14 \%$ of that of the invasive parent species, $R$. frangula (Jacquart and Knight, 2010). Furthermore, assessment of invasive sacred bamboo (Nandina domestica Thunb.) suggests that some cultivars such as 'Firepower' have reduced dispersal potential, are unlikely to invade natural areas, and are suitable for landscape use (Fox et al., 2008). Favorable pollination and germination conditions in our study provided an effective evaluation of triploid reproductive potential.

In addition to reduced fertility of triploid clones of $M$. sinensis, the limited progeny derived from triploid maternal parents were predominantly aneuploids, which can exhibit (or in successive generations lead to) reduced fitness and fecundity (Ramsey and Schemske, 1998). The production of mostly aneuploidy progeny further supports use of low-fertility triploid Miscanthus as landscape plants. Despite triploid pollen being greater than $50 \%$ stainable with acetocarmine, data here suggest that successful $2 x \times 3 x$ and $3 x \times 3 x$ fertilization events were very rare. Therefore, this study provided optimal conditions for triploid fertilization as a result of an abundant supply of diploid pollinators. Seed production by triploid plants isolated from diploids may be extremely rare and will be examined in future experiments. This study concludes that some triploid Miscanthus display substantial reductions (greater than 95\%) in fertility compared with diploid controls despite being phenotypically similar. Several of these clones with substantial reductions in fertility may provide desirable, noninvasive substitutes to highly fertile diploids.

\section{Literature Cited}

Anderson, N.O., N. Gomez, and S.M. Galatowitsch. 2006. A non-invasive crop ideotype to reduce invasive potential. Euphytica 148:185-202.

Barney, J.N. and J.M. DiTomasa. 2008. Nonnative species and bioenergy: Are we cultivating the next invader? Bioscience 58:64-70.

Buggs, R.J.A., A.N. Doust, J.A. Tate, J. Koh, K. Soltis, F.A. Feltus, A.H. Paterson, P.S. Soltis, and D.E. Soltis. 2009. Gene loss and silencing in Tragopogon miscellus (Asteraceae): Comparison of natural and synthetic allotetraploids. Heredity 103:73-81.

Chiang, Y.-C., B.A. Schall, C.-H. Chou, S. Huang, and T.-Y. Chiang. 2003. Contrasting selection modes at the ADH1 locus in outcrossing Miscanthus sinensis vs. inbreeding Miscanthus condensatus (Poaceae). Amer. J. Bot. 90:561-570.

Colautti, R.I., I.A. Grigorovich, and H.J. MacIsaac. 2006. Propagule pressure: A null model for biological invasions. Biol. Invas. 8:1023-1037.

Darke, R. 2007. The encyclopedia of grasses for living landscapes. 2nd Ed. Timber Press, Portland, OR.
Davis, A.S., D.A. Landis, V. Nuzzo, B. Blossey, E. Gerber, and H.L. Hinz. 2006. Demographic models inform selection of biocontrol agents for garlic mustard (Alliaria petiolata). Ecol. Appl. 16:2399-2410.

Doležel, J. and J. Bartos. 2005. Plant DNA flow cytometry and estimation of nuclear genome size. Ann. Bot. (Lond.) 95:99-110.

Doležel, J., J. Greilhuber, S. Lucretti, A. Meister, M.A. Lysa'k, L. Nardi, and R. Obermayer. 1998. Plant genome size estimation by flow cytometry: Inter-laboratory comparison. Ann. Bot. (Lond.) $82: 17-26$.

Eckert, B., O.B. Weber, G. Kirchhof, A. Halbritter, M. Stoffels, and A. Hartmann. 2001. Azospirillum doebereinerae sp. nov., a nitrogen-fixing bacterium associated with the $\mathrm{C}_{4}$-grass Miscanthus. Intl. J. Syst. Evol. Microbiol. 51:17-26.

Fox, A.M., D.R. Gordon, J.A. Dusky, L. Tyson, and R.K. Stocker. 2008. Institute of Food and Agricultural Sciences (IFAS) assessment of nonnative plants in Florida's natural areas-Status assessment. 5 June 2009. <http://plants.ifas.ufl. edu/assessment $/>$.

Friedman, J. and C.H. Barrett. 2011. The evolution of ovule number and flower size in windpollinated plants. Amer. Nat. 177:246-257.

Glowacka, K. and S. Jezowski. 2009. Genetic and nongenetic factors influencing callus induction in Miscanthus sinensis (Anderss.) anther cultures. J. Appl. Genet. 50:341-345.

Heaton, E.A., F.G. Dohleman, A. Fernando Miguez, J.A. Juvik, V. Lozovaya, J. Windholm, O.A. Zabottina, G.F. Mcisaac, M.B. David, T.B. Voight, N.N. Boersma, and S.P. Long. 2010. Miscanthus: A promising biomass crop. Adv. Bot. Res. 56:75-137.

Herbert, C.J., D.H. Touchell, T.G. Ranney, and A.V. LeBude. 2010. In vitro shoot regeneration and polyploid induction of Rhododendron 'Fragrantissimum Improved'. HortScience 45:801-804.

Hirata, M., N. Hasegawa, K. Nogami, and T. Sonoda. 2007. Evaluation of forest grazing as a management practice to utilize and control Miscanthus sinensis in a young tree plantation in southern Kyushu, Japan. Grassland Sci. 53:181-191.

Hodkinson, T.R., M.W. Chase, M.D. Lledo, N. Salamin, and S.A. Renvoize. 2002. Phylogenetics of Miscanthus, Saccharum and related genera (Saccharinae, Andropogoneae, Poaceae) based on DNA sequences from ITS nuclear ribosomal DNA and plastid trnL intron and trnL-F intergenic spacers. J. Plant Res. 115:381-392.

Jacquart, E.M. and T.M. Knight. 2010. Are there noninvasive cultivars of buckthorn? Indiana Nursery \& Landscape News May/June:16-17.

Leitch, I.J., L. Hanson, K.Y. Lim, A. Kovarik, M.W. Chase, J.J. Clarkson, and A.R. Leitch. 2008. The ups and downs of genome size evolution in polyploid species of Nicotiana (Solanaceae). Ann. Bot. (Lond.) 101:805-814.

Lim, K.B., M.S. Ramanna, E. Jacobsen, and J.M. van Tuyl. 2003. Evaluation of $\mathrm{BC}_{2}$ progenies derived from $3 \mathrm{x}-2 \mathrm{x}$ and $3 \mathrm{x}-4 \mathrm{x}$ crosses of Lilium hybrids: A GISH analysis. Theor. Appl. Genet. 106:568-574.

Linde-Laursen, I. 1993. Cytogenetic analysis of Miscanthus 'Giganteus', an interspecific hybrid. Hereditas 119:297-300.

Lo, E.Y.Y., S. Stefanovic, and T.A. Dickenson. 2009. Population genetic structure of diploid sexual and polyploid apomictic hawthorns (Crataegus; Rosaceae) in the Pacific Northwest. Mol. Ecol. 18:1145-1160.

MacFarlane Smith, W.H., J.K. Jones, and A.R. Sebastiampillai. 1989. Pollen storage of Fragaria and Potentilla. Euphytica 41:65-69. 
Martínez-Ghersa, M.A. and C.M. Ghersa. 2006. The relationship of propagule pressure to invasion potential in plants. Euphytica 148: 87-96.

Meyer, M.H. and C.L. Tchida. 1999. Miscanthus Anderss. produces viable seed in four USDA hardiness zones. J. Environ. Hort. 17:137-140.

Norrmann, G.A. and C.L. Quarin. 1987. Permanent odd polyploidy in a grass (Andropogon ternatus). Genome 29:340-344.

Norrmann, G.A. and K.H. Keeler. 2003. Cytotypes of Andropogon gerardii Vitman (Poaceae): Fertility and reproduction of aneuploids. Bot. J. Linn. Soc. 141:95-103.

Ochatt, S.J., E.M. Patat-Ochatt, and A. Moessner. 2011. Ploidy level determination within the context of in vitro breeding. Plant Cell Tissue Organ Cult. 104:329-341.

Ohtsuka, T., T. Sakura, and M. Ohsawa. 1993. Early herbaceous succession along a topographical gradient on forest clear-felling sites in mountainous terrain, central Japan. Ecol. Res. 8:329-340.

Oregon Department of Agriculture. 2011. Buddleja amendment. 4 Mar. 2011. <http://www.oregon. gov/ODA/PLANT/NURSERY/buddleja_amend. shtml>.

Quinn, L.D., D.J. Allen, and J.R. Stewart. 2010. Invasiveness potential of Miscanthus sinensis:
Implications for bioenergy production in the United States. GCB Bioenergy 2:310-320.

Ramsey, J. and D.W. Schemske. 1998. Pathways, mechanisms, and rates of polyploidy formation in flowering plants. Annu. Rev. Ecol. Syst. 29: 467-501.

Ramula, S., T.M. Knight, J.H. Burns, and Y.M. Buckley. 2008. General guidelines for invasive plant management based on comparative demography of invasive and native plant populations. J. Appl. Ecol. 45:1124-1133.

Rayburn, A.L., J. Crawford, C.M. Rayburn, and J.A. Juvik. 2009. Genome size of three Miscanthus species. Plant Mol. Biol. Rpt. 27: 184-188.

Sears, E.R. 1953. Addition of the genome of Haynaldia villosa to Triticum aestivum. Amer. J. Bot. 40:168-174.

Shea, K. and D. Kelly. 1998. Estimating biocontrol agent impact with matrix models: Carduus nutans in New Zealand. Ecol. Appl. 8:824-832.

Sheppard, A.W., P. Hodge, Q. Paynter, and M. Rees. 2002. Factors affecting invasions and persistence of broom Cytisus scoparius in Australia. J. Appl. Ecol. 39:721-734.

Slomka, A., P. Kawalec, K. Kellner, M. JedrzejczykKorycinska, A. Rostanski, and E. Kuta. 2010. Was reduced pollen viability in Viola tricolor $\mathrm{L}$. the result of heavy metal pollution or rather the tests applied? Acta Biol. Cracoviensia 52:123127.

Soltis, D.E., P.S. Soltis, and J.A. Tate. 2003. Advances in the study of polyploidy since plant speciation. New Phytol. 161:173-191.

Stewart, J.R., Y. Toma, F.G. Fernandez, A. Nishiwakis, T. Yamada, and G. Bollero. 2009. The ecology and agronomy of Miscanthus sinensis, a species important to bioenergy crop development, in its native range in Japan: A review. GCB Bioenergy 1:126-153.

Tel-Zur, N., S. Abbo, and Y. Mizrahi. 2005. Cytogenetics of semi-fertile triploid and aneuploid intergenetic vine cacti hybrids. J. Hered. 96:124-131.

Tozer, K.N., D.F. Chapman, P.E. Quigley, P.M. Dowling, R.D. Cousens, G.A. Kearney, and J.R. Sedcole. 2008. Controlling invasive annual grasses in grazed pastures: Population dynamics and critical gap sizes. J. Appl. Ecol. 45: 1152-1159.

Tsuyuzaki, S. and A. Hase. 2005. Plant community dynamics on the volcano Mount Koma, northern Japan, after the 1996 eruption. Folia Geobot. 40:319-330.

Wilson, S.B. and G.W. Knox. 2006. Landscape performance, flowering, and seed viability of 15 Japanese silver grass cultivars grown in northern and southern Florida. HortTechnology 16:686-693. 